http://jmscr.igmpublication.org/home/ ISSN (e)-2347-176x ISSN (p) 2455-0450 crossref DOI: https://dx.doi.org/10.18535/jmscr/v9i6.10

\title{
Spinal Anaesthesia Using Taylors Lumbosacral Approach to Reduce the Incidence and Severity of Hypotension in Patients Undergoing Transuretheral Resection of Prostate
}

\author{
Authors \\ Dr Kamini Randhawa ${ }^{1}$, Dr Shweta Mahajan ${ }^{2}$, Dr Arti Sharma ${ }^{3}$ \\ ${ }^{1}$ Junior Resident, Department of Anaesthesiology, Indira Gandhi Medical College, Shimla \\ ${ }^{2}$ Associate Professor, Department of Anaesthesiology, Indira Gandhi Medical College, Shimla \\ ${ }^{3}$ Associate Professor, Department of Anaesthesiology, Indira Gandhi Medical College, Shimla
}

\begin{abstract}
Hypotension are the most common undesired side effects during spinal anaesthesia. Taylor lumbosacral approach of spinal anaesthesia caused less hypotension in patient undergoing TURP. The purpose of the present study was to compare the incidence and severity of hypotension between a lumbar approaches at L4/5 or Taylor's lumbosacral approach. 30 patients received SPA by a L4/5 approach and 30 patients by Taylor's approach. Bupivacaine dose did not differ between groups. Onset of MLSB was faster $(3.17+1.020$ min vs 7.20+1.215, $p<0.001)$ in the lumbar group. Onset of motor block was faster $(5.47+1.358$ min vs $8.40+0.770)$ in lumbar group but duration of motor block did not differ between groups. The maximum decrease in mean arterial pressure was also greater in the lumbar group (60\% vs. 70\%, p value 0.037). SPA with plain bupivacaine using Taylor's approach was associated with slower onset of MLSB and less hypotension compared to the classical lumbar approach at L4/5.
\end{abstract}

\section{Introduction}

Transuretheral resection of prostrate (TURP) is the gold standard surgical intervention for patients with benign prostatic hyperplasia (BPH), which causes urinary obstruction and increases the risk of urinary tract infection ${ }^{1}$. TURP can be performed under spinal anaesthesia or general anaesthesia, however the choice of anaesthetic technique for TURP is spinal anaesthesia as it offers many advantages over general anaesthesia including stable haemodynamic variables, decrease blood loss and post operative pain, less chances of deep venous thrombosis after surgery, decrease post-operative confusion and faster recovery $^{1,2}$. Spinal anaesthesia is performed through midline, paramedian or Taylors lumbosacral approach. ${ }^{3}$ Midline approach of spinal anaesthesia is the most commonly used technique but it has got limitations in patients who cannot flex adequately because of pain and ossified ligaments in old age. In these patients paramedian approach is very useful ${ }^{4}$. In 1940 Taylor described modified paramedian approach (Taylor or lumbosacral approach) via $\mathrm{L}_{5}-\mathrm{S}_{1}$ space which causes less hypotension ${ }^{5}$. The $\mathrm{L}_{5}-\mathrm{S}_{1}$ intervertebral space is largest intevertebral space and is least likely to be obliterated by pathological processes such as degeneration, extensive scarring and obliteration of interspinal spaces. So, Taylor approach is helpful in cases of technical difficulty 
in establishing the successful subarachnoid block in patients with deformed spine due to scoliosis, kyphoscoliosis or arthritis. Thus Taylors approach offers an additional advantage in patient with difficult neuraxial anatomy as it avoids multiple punctures and consequently the higher risk of complications such as neurological complications and PDPH (post dural puncture headache) is decreased $^{6}$. In 2006 Litz et $^{5}$ al described spinal anaesthesia using Taylor lumbosacral approach reducing the incidence and severity of hemodynamic side effect in patient undergoing transuretheral surgery. Considering all these merits of Taylor lumbosacral approach of spinal anaesthesia, the aim of our study was to compare the incidence and severity of hypotension between lumbar approach at L3-L4 and Taylors lumbosacral approach at L5-S1 interspace in patient undergoing TURP.

\section{Aims and Objectives}

To compare the incidence and severity of hypotension between a lumbar approach at $\mathrm{L}_{3}-\mathrm{L}_{4}$ and Taylor's lumbosacral approach at $\mathrm{L}_{5^{-}}$ $\mathrm{S}_{1}$ interspace in patient undergoing TURP.

\section{Material and Methods}

After approval by the research and ethical committee and written informed consent of the patient, the study was carried out in ASA I and ASA II patients, aged between 30 -70 years, posted for TURP at IGMC, Shimla. The study was conducted in controlled prospective randomized manner from July 2018 to July 2019. The patients were assigned to their respective groups using random allocation software. ASA I and ASA II, diagnosed case of BPH, male patient aged between 30-70 years Scheduled for TURP were included in study. Patients refusal to participate in the study, ASA class III and above, hypersensitivity to local anaesthetic, contraindication to spinal anaesthesia and patients on anticoagulant and antiplatelet drugs were excluded from study. Patients were divided into two groups Group $\mathrm{C} \&$ Group $\mathrm{T}$ using random allocation software with 30 patients in each group receive conventional approach and Taylors lumbosacral approach of spinal anaesthesia with 3 $\mathrm{ml}$ of bupivacaine $0.5 \%$ hyperbaric solution respectively. All patients were preoperatively evaluated clinically, with routine investigations. Informed written consent to be taken from all patient included in the study .The patients were kept fasting for 8-10 hrs overnight and premedicated with tablet alprazolam $0.50 \mathrm{mg}$ per orally night before surgery and 3 hour prior to surgery with sip of water. Patient was shifted to operation theatre, Intravenous access was secured and IV fluid started. Patients was monitored for heart rate (H.R), lead II electrocardiography (ECG), pulse oximetry (Spo2) and non invasive blood pressure (NIBP) every 5 min during surgery .The patient was positioned in sitting position. After cleaning and draping, the allocated interspace was identified by palpation. Then $2 \mathrm{ml}$ of $2 \%$ plain lignocaine was infiltrated on the skin. The lumbar puncture was performed with 26 gauze spinal needle in the sitting position using midline approach at $\mathrm{L}_{3}-\mathrm{L}_{4}$ interspace for $\mathrm{C}$ group and $\mathrm{L}_{5}-\mathrm{S}_{1}$ interspace by using Taylors approach for $\mathrm{T}$ group. After identification of needle placement by free flow of cerebrospinal fluid, the subarachnoid block was established by administrating $3 \mathrm{ml}$ of $0.5 \%$ bupivacaine hyperbaric solution and patient was turned to the supine position and left in supine position for 10 minute. onset of sensory block was assessed from the time of injecting drug into subarachnoid space till complete analgesia at the level of T-10 was achieved. Maximum Level of sensory block was checked bilaterally by pin prick method with 23 gauge hypodermic blunt needle and dermatomal level was tested every 2 min until the highest level was stabilized for four consecutive tests. The onset of motor block was assessed every 2 minutes till complete motor block was achieved as per Modified Bromage Scale. The duration of motor block was taken as the time from complete motor block (Modified Bromage 1) to time when lower limb can be moved freely (Modified 
Bromage 6). Hypotension (mean blood pressure recording less than $20 \%$ of baseline) if any patient were treated with help of intravenous fluid bolus and incremental doses of vasopressor agent mephentermine $6 \mathrm{mg}$ i.v. Data collected was entered and analyzed in excel sheet, using appropriate statistical software and test of significance .

\section{Results}

Demographic distribution in two groups were similar with no significant difference as shown in table 1. Mean age (in years) in group $\mathrm{C}$ was $66.63+8.620$ and in group $\mathrm{T}$ was $64.40+7.064$.

Table 1: Demographic Data (Age Distribution)

\begin{tabular}{|l|c|c|c|c|}
\hline \multirow{2}{*}{ Sr .No } & \multirow{2}{*}{ Group of Patients } & \multicolumn{3}{|c|}{ Age } \\
\cline { 3 - 5 } & & Mean & S.D & p-value \\
\hline 1 & $\mathrm{C}$ & 66.63 & 8.620 & 0.27 \\
\hline 2 & $\mathrm{~T}$ & 64.40 & 7.064 & \\
\hline
\end{tabular}

The onset of sensory block was delayed in the group $\mathrm{T}$ and this difference was found to be highly significant statistically ( $p$-value less than 0.001). Mean time to achieve maximum level of sensory block in group $\mathrm{C}$ was $5.70+1.022$ and group $\mathrm{T}$ was $10.33+1.184$. It was delayed in group $\mathrm{T}$ that come out to be highly significant statistically. Mean onset of motor block (in minute) in group $\mathrm{T}$ was $8.40+0.77$ and in group $C$ was $5.47+1.35$. It was delayed in group $\mathrm{T}$ that come out to be highly significant statistically. Mean duration of motor block (in minutes) in group $\mathrm{C}$ and group $\mathrm{T}$ was $219.23+18.122$ and $215.43+19.415$ respectively. $\mathrm{P}$ value was 0.436 which was not significant statistically as shown in table 2 .

Table 2: Comparison between group $\mathrm{C}$ and group $\mathrm{T}$

\begin{tabular}{|l|c|c|c|}
\hline \multirow{2}{*}{ Parameters } & \multicolumn{2}{|c|}{ Mean + S.D } & p-value \\
\cline { 2 - 3 } & $\mathrm{C}$ & $\mathrm{T}$ & \\
\hline $\begin{array}{l}\text { Onset of sensory block } \\
\text { (in minutes) }\end{array}$ & $3.17+1.020$ & $7.20+1.215$ & 0.000 \\
\hline Onset of motor block (in minutes) & $5.47+1.358$ & $8.40+0.770$ & 0.000 \\
\hline $\begin{array}{l}\text { Time to achieve maximum sensory level } \\
\text { (in minutes) }\end{array}$ & $5.70+1.022$ & $10.33+1.184$ & 0.000 \\
\hline Duration of motor block(in minutes) & $219.23+18.122$ & $215.43+19.415$ & 0.436 \\
\hline
\end{tabular}

The incidence of hypotension (mean blood pressure less than $20 \%$ of baseline) in group C was $60 \%$ and in group $\mathrm{T}$ was $30 \%$. Therefore, this incidence of hypotension was found to be statistically significant between the two groups. (p-value less than 0.05) as shown in table 3

Table 3- Assessment of side effects

\begin{tabular}{|l|c|c|c|c|c|}
\hline \multirow{2}{*}{ Parameter } & \multicolumn{2}{|c|}{ Group C } & \multicolumn{2}{c|}{ Group T } & \multirow{2}{*}{ p-value } \\
\cline { 2 - 5 } & Number & $\%$ age & Number & \%age & \\
\hline Hypotension & 18 & 60 & 9 & 30 & 0.019 \\
\hline
\end{tabular}

\section{Discussion}

Spinal anaesthesia is safe, reliable and inexpensive modality for transurethral resection of prostrate with the additional advantage of providing stable hemodynamics, decreased blood loss, prolonged post operative pain relief, less chances of deep vein thrombosis after surgery, decreased postoperative confusion and faster recovery ${ }^{2}$. As Most of patients are elderly with multiple co- morbidities, increased hemodynamic alterations are expected in patients undergoing transuretheral resection of prostrate under 
subarachnoid block ${ }^{2}$. Our study was comparable with the study conducted by Litz et $\mathrm{al}^{5}$ in the year 2006 who found significant difference in the onset of sensory block between the lumbar group and Taylor group. Onset of sensory block was slower in Taylor group as compared to lumbar group , Onset of maximum level of sensory block in lumbar and Taylor groups were 17.8 \pm 6.5 minutes and 22.6 \pm 6.7 minutes respectively which was statistically significant ( $\mathrm{p}$ value less than 0.001 ), onset of motor blockade in two group significant but no difference in duration of motor block between group $\mathrm{C}$ and group $\mathrm{T}$, incidence of hypotension in lumbar group was $14.9 \pm 8.6 \%$ and in Taylor group was $10.5 \pm 8.3 \%$ and the difference was found to be statistically significant ( $\mathrm{p}$ value less than 0.001).

\section{Conclusion}

Taylor's approach of spinal anaesthesia was associated with delay in the onset of sensory block and motor block along with slower time for maximum level of sensory block and lesser incidence of hypotension and bradycardia. We observed that the Taylor approach of spinal anaesthesia in TURP patients was associated with less hypotension. Thus we concluded that Taylor's approach of spinal anaesthesia is superior to conventional approach of spinal anaesthesia for patient undergoing transuretheral resection of prostrate with decreased incidence and severity of hypotension.

\section{References}

1. Aidan $\mathrm{M} O$ Donnell, Irwin $\mathrm{TH}$ Foo $\mathrm{MB}$ BChir. Anaesthesia for transuretheral resection of the prostrate. $\mathrm{Br} J$ Anaesth 2009; 9(3): 92-6.

2. Vitalis Mung'ayi, Karen Mbaya, Thikra Sharif, Dorothy Kamya. A randomized controlled trial comparing haemodynamic stability in elderly patients undergoing spinal anaesthesia at $\mathrm{L}_{5}-\mathrm{S}_{1}$ versus spinal anaesthesia at $\mathrm{L}_{3}-\mathrm{L}_{4}$ at a tertiary African hospital. African health science 2015; 15(2): 466-79.

3. Md. Rafiqul Islam, Mozaffer Hossain, Quazi Arefin Kabir, Abdul Alim. Paramedian approach for subarachnoid blockade - A marvelous technique having less attention. Journal of BSA 2006; 19: 51-3.

4. Dr. P. Chalapathy, Dr. E. Jayasundaram. Taylors approach is best apporoach to overcome difficulty in lumbar puncture in difficult spinal cases. IORS-JDMS 2016;15-12

5. Litz, R.J, Brandt, M.; Wiessner, D.; Heller, A.R.; Koch, T. spinal anaesthesia using Taylors lumbosacral approach reducing incidence and severity of hemodynamic side effect in patient undergoing transuretheral surgery. EJA 2006; 23: 114.

6. Kumkum Gupta, Bhawna Rastogi, Prashant K .Gupta, Avinash Rastogi, Manish Jain and V.P.Singh.Subarachnoid block with Taylors approach for surgery of lower half of body and lower limb:A clinical study. Anesth Essays Res.2012; 6(1): 38-41. 